\title{
Pengaruh Pengawasan Dan Motivasi Terhadap Disiplin Kerja Pegawai Pada Dinas Pariwisata Dan Kebudayaan Kabupaten Karo
}

\author{
Menanti Sembiring ${ }^{1)}$ Ingan Ukur Sitepu ${ }^{2)}$ \\ ${ }^{1) 2)}$ Dosen Fakultas Ekonomi Universitas Quality \\ Email : sembiringmenanti@gmail.com
}

\begin{abstract}
Abstrak
Penelitian ini bertujuan untuk mengetahui bagaimana pengaruh pengawasan dan motivasi kerja terhadap disiplin kerja pegawai Dinas Pariwisata dan Kebudayaan Kabupaten Karo. Jumlah populasi penelitian ini adalah sekitar 37 orang dan semuanya dijadikan sebagai sampel atau sampel total. Untuk menguji hipotesis yang diajukan dilakukan pengujian parsial, pengujian simultan dan koefisien determinasi. Hasil penelitian menunjukkan bahwa secara parsial, variabel pengawasan dan motivasi berpengaruh signifikan terhadap disiplin kerja pegawai Dinas Pariwisata dan Kebudayaan Kabupaten Karo, dimana nilai t hitung dalam variabel pengawasan adalah 2.272 dan nilai yang dihitung berdasarkan variabel movasi adalah 4.431, dimanapun nilai t tabel adalah 1.687. Dengan cara uji simulatan, Fhitung dihitung dengan 32, 112 dan nilai Ftabel adalah 3.267. Dapat disimpulkan bahwa dengan cara uji simultan, variabel pengawasan dan motivasi berpengaruh signifikan terhadap disiplin kerja pegawai di Dinas Pariwisata dan Kebudayaan Kabupaten Karo. Hasil regresi linier berganda diperoleh dengan persamaan $\mathrm{y}=9,516+0,2321 \mathrm{X}_{1}+0,497 \mathrm{X}_{2}+\mathrm{e}$. Nilai koefisien determinasi menyatakan bahwa 0,654 atau 65,40\% disiplin kerja pegawai di Dinas Pariwisata dan Kebudayaan Kabupaten Karo dipengaruhi oleh pengawasan dan motivasi dan sisanya $34,60 \%$ dipengaruhi oleh faktor lain yang tidak diteliti dalam penelitian ini.
\end{abstract}

Kata kunci : Pengawasan, motivasi, disiplin kerja

\begin{abstract}
This research is aim to find out how the influence of supervision and working motivation towards discipline of work to employee of Tourism and Culture Department, Karo District. The number of population on this research is about 37 people and all of those made as sample or total sample. For verifying hypothesis which is proposed, there will be done with partial examination, simultaneous examination, and coefficient of determination. The result shows that in partially, variable of supervission and motivation influences discipline of work to employee of Tourism and Culture Department significantly, where the value of $t_{\text {calculated }}$ in supervission variable is 2.272 and value that is calculated according to variable of motivation is 4.431, whereever value of $t_{\text {table }}$ is 1.687 . While with simultaneous examination, $F_{\text {calculated }}$ is calculated with 32,112 and the value of $F_{\text {table }}$ is 3.267. So, it is concluded that with simultaneous examination, variable of supervission and motivation influences discipline of work to employee of Tourism and Culture Department significantly too. The result of multiple linear regression
\end{abstract}


obtained with this equation, $y=9,516+0,2321 X_{1}+0,497 X_{2}+e$. The Coefficient of determination stated that 0,654 or 65,4\% of discipline of work to employee of Tourism and Culture Department is influenced by supervission and motivation and the residual 34,6\% is influenced by another factor which isn't researched on this study.

Keywords : supervission,motivation, discipline of work

\section{PENDAHULUAN}

Peranan sumber daya manusia dalam organisasi sangatlah penting karena merupakan penggerak utama dari semua kegiatan dalam mencapai tujuan organisasi yang telah direncanakan. Karena itu berhasil tidaknya suatu organisasi dalam mempertahan kanek lsistensinya akan dimulai dari kemampuan manajemen mengelola sumberdaya manusianya. Demikian halnya Dinas Pariwisata dan Kebudaayaan Kabupaten Karo yang merupakan salah satu Satuan Kerja Perangkat Daerah yang memiliki tugas menyelenggarakan urusan Pemerintah Daerah di bidang pariwisata dan kebudayaan di Kabupaten Karo

Sebagai aparatur negara maka satu hal yang harus dimiliki oleh setiap pegawai adalah kedisiplinan. Dengan disiplin yang baik maka setiap pegawai akan dapat melaksanakan pelayanannya kepada masyarakat dengan baik. Namun kenyataan di lapangan belum seperti yang diharapkan masih ada pegawai yang tidak bekerja pada jam kerja atau memanfaatkan waktu kerja untuk hal-hal diluar tugas atau pekerjaannya. Masih kurangnya disiplin kerja ini bisa terjadi karena belum optimalnya pelaksanaan pengawasan yang dilakukan dan bisa juga karena motivasi kerja pegawai masih kurang. Adanya motivasi ini mendorong seseorang untuk melakukan kegiatan -kegiatan tertentu guna mencapai suatu tujuan.

Pengawasan dan motivasi kerja merupakan suatu hal yang dapat meningkatan kinerja pegawai. Orang yang paling tepat untuk melakukan pengawasan maupun memotivasi pegawai adalah pimpinan sebagai atasan langsung dari pegawai yang dianggap paling tahu dan paling dekat dengan bawahannya. Oleh karena itu pimpinan harus melakukan pengawasan kerja yang efktif untuk mencegah terjadinya penyimpangan, dan memberi motivasi yang tepat agar semangat kerja setiap pegawai tetap tinggi. Pengawasan dapat dilakukan dengan mengevaluas dan menilai pekerjaan pegawai, mencegah terjadinya kesalahan kerja, dan mengadakan perbaikan jika terjadi kesalahan.

Menurut Manullang (2009:173) : pengawasan merupakan sebagai suatu proses untuk menerapkan pekerjaan apa yang sudah dilaksanakan, menilainya, dan bila perlu mengoreksi dengan maksud supaya pelaksanaan pekerjaan sesuai dengan rencana semula. 
Agar pelaksanaan pekerjaan dapat berjalan dengan baik maka pengawasan dapat dilakukan dengan berbagai cara seperti yang yang disebutkan oleh Nawawi dalam Kadarisman (2012: 213) ;

a) Pengawasan melekat (Waskat), yang diartikan sebagai : 1) proses pemantauan, pemeriksaan dan evaluasi oleh pimpinan unit/organisasi kerja terhadap fungsi semua komponen dalam melaksanakan pekerjaan di lingkungan suatu organisasi nonprofit; 2) pengawasan melekat (Waskat), yang diartikan sebagai proses pemantauan,

pemeriksaan, dan evaluasi oleh pimpinan unit/ organisasi kerja terhadap pendayagunaan semua sumberdaya, untuk mengetahui kelemahan/ kekurangan dan kelebihan/ kebaikan, yang dapat digunakan untuk pengembangan unit/ organisasi kerja di masa depan.

b) Pengawasan fungsional (Wasnal) adalah proses pemantauan,

pemerikasaan, dan evaluasi oleh aparatur pengawasan dalam sistem pemerintahan yang fungsi dan tugas pokoknya khusus di bidang pengawasan. Badan tersebut adalah Badan Pemeriksa Keuangan, Inspektorat Jenderal Pembangunan

(IRJENBANG), Badan Pengawasan Keuangan dan Pembangunan (BPKP). Proses pengawasannya terutama dilakukan untuk mengetahui apakah pelaksaan pekerjaan pihak yang diawasi telah sesuai dengan perencanaan dan peraturan perundangundangan yang berlaku. C) Pengawasan masyarakat (Wasmas), adalah setiap pengaduan, kritik, saran, pertanyaan, dan lain-lain yang disampaikan anggota masyarakat mengenai pelaksanaan pekerjaan oleh unit/ organisasi kerja nonprofit di bidang pemerintahan dalam melaksanakan tugas pokoknya memberikan pelayanan umum (public service) dan pembangunan untuk kepentingan kehidupan bermasyarakat, berbangsa, dan bernegara.

c) Pengawasanmerupakanba giantidakterpisahkandala mpenyelenggarankegiatan suatuorganisasi.

Suatupengawasandikatak anpentingkarenatanpaada nyapengawasan yang 
baiktentunyaakanmengha silkantujuan yang kurangmemuaskan, baikbagiorganisasiitusend irimaupunpekerjaanya.

Adanya pengawasan yang baik dalam organisasi adalah untuk memastikan bahwa semua yang telah direncanakan telah terlaksana sebagaimana mestinya.

Melalui pengawasan yang yang dilakukan dengan baik maka diharapkan semua kegiatan yang dijalankan sesuai dengan yang telah direncanakan dan jika terjadi penyimpangan maka dapat dengan segera diperbaiki.

Lebih lanjut Kadarisman (2012 : 211), menyatakan : indikasi jika pengawasan dilakukan dengan baik yakni :

1. Meningkatnya disiplin dan prestasi kerja karyawan.

2. Pengurangan tingkat penyalahgunaan wewenang dan berkurangnya kebocoran dan pemborosan serta berbagai pungutan.

3. Semakin berkurangnya kesalahan kesalahan dalam pelaksanaan pekerjaan.

Selain pengawasan satu hal yang dikira sangat penting agar tujuan organisasi dapat tercapai adalah pegawai harus memiliki motivasi yang tinggi dalam bekerja.
Seorang pegawai yang memiliki motivasi kerja yang tinggi akan memiliki semangat kerja yang tinggi dan biasanya mereka akan mengerjakan tugas yang menjadi jawabnya

Menurut Agustini (2011: 32), motivasi pegawai adalah: " Faktorfaktor yang mengarahkan dan mendorong perilaku atau keinginan seseorang untuk melakukan suatu kegiatan yang dinyatakan dalam bentuk yang keras atau lemah". Seorang pegawai yang memilki motivasi yang tinggi akan bekerja dengan semangat yang tinggi sebaliknya pegawai yang memilki motivasi yang rendah akan memiliki semangat kerja yang rendah untuk melaksanakan pekerjaannya.

Mengingat pentingnya motivasi tersebut maka sudah selayaknyalah seorang pimpinan harus bisa memahami apa sebenarnya kebutuhan yang dapat memengaruhi bawahannya sehingga mereka bertingkah laku tertentu. Dengan mengetahui hal tersebut maka seorang pemimpinan akan lebih mudah memotivasi bawahannya, agar perilaku bawahan dapat diarahkan guna pencapaian tujuan organisasi. 
Menurut Sutrisno (2011: 147), agar pemberian motivasi dapat mencapai tujuannya maka seorang pimpinan harus bisa menggunakan keahliannya, yakni :

1. Menciptakan iklim kerja yang menyenangkan.

2. Memberikan penghargaan dan pujian bagi yang berprestasi dan membimbing yang belum berprestasi;

3. Membagi tugas sesuai dengan kemampuan para bawahan;

4. Memberi umpan balik tentang pekerjaan;

5. Memberi kesempatan bawahan untuk maju dan berkreativitas

Pemberian motivasi yang dilakukan oleh pimpinan dilakukan dengan memperhatikan situasi dan kondisi. Pimpinan harus mampu memilih kapan dilakukan cara pemberian motivasi positif dan kapan memberikan cara motivasi negatif . Dengan pemilihan cara yang tepat maka diharapkan pegawai dapat lebih meningkatkan prestasi kerjanya untuk mencapai tujuan organisasi. Setiap pegawai akan terdorong untuk bekerja keras dan antusias dengan mengerahkan segala kemampuannya secara optimal dalam melaksanakan tugas yang menjadi tanggung jawabnya.

Menurut David C. Mc.Celland dalam Mangkunegara (2011: 103) ada beberapa kareteristik orang yang memilki motiv berprestasi yang tinggi, yaitu :

1. Memiliki tingkat tanggung jawab pribadi yang tinggi

2. Berani mengambil dan memikul risiko

3. Memiliki tujuan yang realistik

4. Memiliki rencana kerja yang menyeluruh dan berjuang untuk merealisasi tujuan

5. Memanfaatkan umpan balik yang konkrit dalam semua kegiatan yang dilakukan

6. Mencari kesempatan untuk merealisasikan rencana yang telah diprogramkan.

Keberhasilan organisasi dalam merealisasikan semua rencana kerjanya tidak terlepas dari disiplin kerja pegawainya. Untuk itu setiap organisasi perlu membuat berbagai ketentuan yang harus ditaati oleh semua anggota organisasinya.

MenurutUndang-

UndangNomor 53 Tahun 2010 TentangDisiplinPegawaiNegeriSipil : Disiplin Pegawai Negeri Sipil adalah kesanggupan Pegawai Negeri Sipil untuk menaati kewajiban dan 
menghindari larangan yang ditentukan dalam peraturan perundang-undangan dan/atau peraturan kedinasan yang apabila tidak ditaati atau dilanggar dijatuhi hukuman disiplin.

Dari uraian diatas dapat dikatakan bahwa pegawai memiliki kewajiban untuk menjalankan semua peraturan yang ada, mengerjakan tugas dan tanggung jawabnya dan bila pegawai tersebut melanggar peraturan maka yang bersangkutan akan dijatuhi sanksi pendisiplinan sesuai dengan undang-undang yang berlaku.

Menurut Siagian (2015: 305) $(2011 ; 74)$ terdapatdua jenisdisiplin dalam organisasi, yaitu yang bersifat preventif dan yang bersifat korektif.

Melalui pendisiplinan preventif diharapkan semua pegawai terdorong untuk taat dan patuh terhadap semua ketentuan yang berlaku dalam organisasi. Tujuan pendisiplinan ini untuk mendidik pegawai mendisiplinkan dirinya sendiri. Pegawai dengan kesadarannya sendiri selalu mematuhi semua peraturan yang ada dalam organisasi. Sedangkan melalui disiplin korektif jika ada pegawai yang melanggar peraturan maka akan diberikan sanksi sesuai dengan kesalahan yang dilakukan dengan tujuan agar pegawai yang $b$ ersangkutan tidak mengulangi kesalahan yang sama dikemudian hari. Tujuan pendisiplinan korektif untuk memberikan efek jera bagi karyawan yang tidak disiplin, juga bagi karyawan yang lain agar tidak melaanggar disiplin kerja.

\section{METODE PENELITIAN}

Populasi dalam penelitian ini adalah semua pegawai negeri sipil yang ada pada Dinas Pariwisata dan Kebudayaan Kabupaten Karo yang berjumlah 37orang Karena jumlah populasinya jumlahnya kecil maka semua populasi dijadikan sampel penelitian (sampel jenuh). Yang menjadi variabel penelitian terdiri dari Variabel bebas (X), yakni: Variabel Pengawasan $\left(\mathrm{X}_{1}\right)$ dan Variabel Motivasi $\left(\mathrm{X}_{2}\right)$ dan variabel terikat (Y) adalah Disiplin Kerja Pegawai Dinas Pariwisata dan Kebudayaan Kabupaten Karo (Y)

Untuk menganalisis data yang dikumpulkan digunakan metode analisis deskriptif dan kuantitatif. Melalui metode deskriptif data dikumpulkan dan ditafsirkan sehingga dapat memberikan gambaran yang jelas atas permasalahan yang sedang diteliti. Sedangkan melalui metode Kuantitatif digunakan metode analisis regresi linier berganda.

Model persamaan regresinya adalah $: \mathrm{Y}=\mathrm{a}+\mathrm{b}_{1} \mathrm{X}_{1}+\mathrm{b}_{2} \mathrm{X}_{2}+\mathrm{e}$

Keterangan :

$\mathrm{Y}=$ Disiplin Kerja

a $=$ Konstanta

$b_{1}, b_{2}=$ Koefisien regresi

$\mathrm{X} 1=$ Pengawasan

$\mathrm{X} 2=$ Motivasi

$\mathrm{E}=$ error of term

Pengujian hipotesis dilakukan dengan cara sebagai berikut :

\section{Uji Parsial (Uji t)}

a. Ho :diterima jika variabelpengawasan $\quad\left(\mathrm{X}_{1}\right)$ dan motivasi kerja $\left(\mathrm{X}_{2}\right)$ 


$\begin{array}{lrlr}\text { secara parsial } & \text { tidak } & \text { kerja } & \text { (Y) } \\ \text { berpengaruh } & \text { signifikan } & \text { denganpengambilankeput } \\ \text { terhadap variable } & \text { disiplin } & \text { usan } F_{\text {hitung }}>F_{\text {tabel }}, \alpha 0,05\end{array}$

pegawai (Y), dengan

pengambilan keputusan $\mathrm{t}$

hitung $<\mathrm{t}_{\text {tabel }}$, pada $\alpha 0,05$

b. $\mathrm{Ha}$ : diterima jika

pengawasan $\left(\mathrm{X}_{1}\right)$ dan

motivasi kerja $\left(\mathrm{X}_{2}\right)$ secara

parsial tidak memiliki pengaruh signifikan terhadap variable disiplin kerja (Y) dengan pengambilan keputusan $\mathrm{t}_{\text {hitung }}>\mathrm{t}_{\text {tabel }}, \alpha 0,05$

\section{Uji Simultan (Uji f )}

a. Ho : diterima jika pengawasan $\left(\mathrm{X}_{1}\right)$ dan motivasi kerja $\left(\mathrm{X}_{2}\right)$ secara simultan tidak berpengaruh signifikan terhadap variable disiplin kerja (Y) dengan pengambilan keputusan $\mathrm{F}$ hitung $<\mathrm{F}_{\text {tabel }}, \alpha 0,05$

b. Ha: diterimajika variable pengawasan $\left(\mathrm{X}_{1}\right)$ dan motivasikerja $\left(\mathrm{X}_{2}\right)$ secara simultan berpengaruh signifikan terhadap variable disiplin

\section{Uji Koefisien Determinasi $\left(\mathbf{R}^{2}\right)$}

Uji koefisien determinasi $\left(\mathrm{R}^{2}\right)$ pada intinya mengukur seberapa besar kemampuan model yang dimasukkan dalam Regresi dapat menerangkan variable terikat. Nilai koefisien determinasi berada antara nol sampai satu. Jika $\mathrm{R}^{2}$ semakin besar (mendekati1) , ini berarti kemampuan variabel bebas dalam menjelaskan variabel terikat sangat besar, sebaliknya jika nilai koefisien mendekati nol maka kemampuan variabel bebas yang dimasukkan dalam model untuk menjelaskan variabel terikat sangat terbatas

\section{Hasil Penelitian dan \\ Pembahasan}

Dari hasil hasil perhitungan regresi linier berganda dengan menggunakan bantuan program SPSS maka diperoleh hasil regresi seperti tertera pada tabel berikut ini. 
a. Dependent Variable: Y

Tabel1 Hasil Uji Analisis Regresi Berganda

Coefficients $^{\mathrm{a}}$

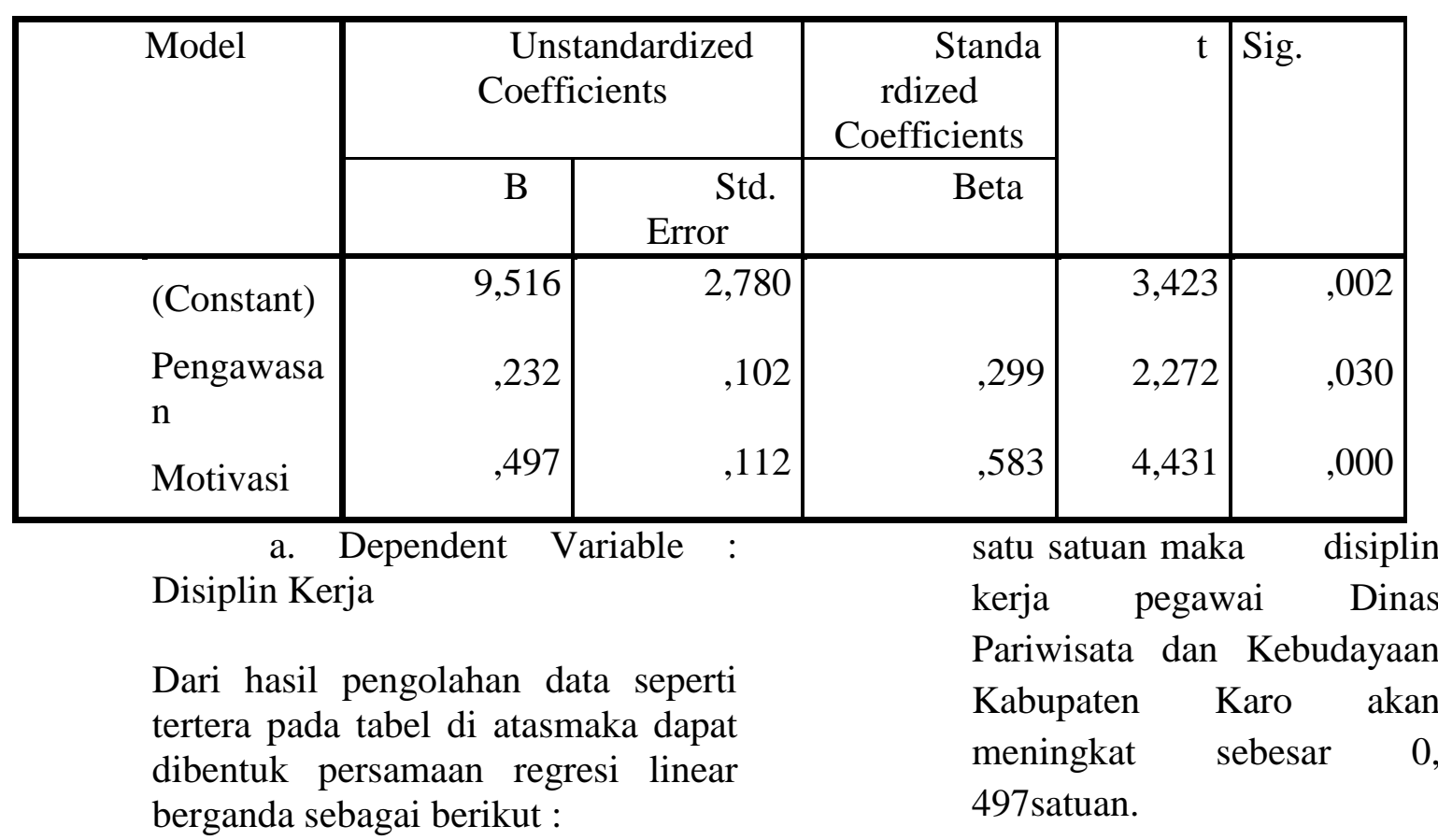

$\mathrm{Y}=9,516+0,232 \mathrm{X}_{1}+0,497 \quad$ Berdasarkan tabel 1 di atas

$\mathrm{X}_{2}+\mathrm{e}$

Keterangan :

1. Nilaikonstanta sebesar 9,516 dapat diartikan jika pengawasan dan motivasi tidak ada maka disiplin kerja pegawai DinasPariwisata dan Kebudayaan akan tetap sebesar 9,516 satuan.

2. Koefisien regresi $X 1$ sebesar 0,232dapat diartikan jika pengawasan kerja ditingkatkan satu satuan maka disiplin kerja pegawai Dinas Pariwisata dan Kebudayaan Kabupaten Karo akan naik sebesar 0,232 satuan

3. Nilai $\mathrm{X} 2=\mathbf{0 , 4 9 7}$ dapat diartikan jika motivasi kerja ditingkatkan sebesar diperoleh nilai $\mathrm{t}$ hitung untuk variabel pengawasan sebesar 2,272 sedangkan nilai t tabel sebesar 1,687 pada $\alpha 5 \%(2,272>1,687)$, dengan demikian maka dapat dikatakan bahwa pengawasan secara parsial berpengaruh signifikan terhadap disiplin kerja pegawai Dinas Pariwisata dan Kebudayaan Kabupaten Karo dapat diterima. Untuk variabel motivasi diperoleh $\mathrm{t}$ hitung sebesar 4,431 dan $\mathrm{t}$ tabel 1,687 ( $\mathrm{t}$ hitung $(4,431)>\mathrm{t}$ tabel $(1,687)$ pada tingkat kepercayaan 5 $\%$ dengan demikianmaka ho ditolak dan ha diterima yang berarti motivasi berpengaruh signifikan terhadap disiplin kerja pegawai Dinas Pariwisata dan Kebudayaan Kabupaten Karo. 
Untuk mengetahui apakah secara simultan variabel pengawasan dan motivasi berpengaruh signifikan terhadap disiplin kerja pegawai pada
Dinas Pariwisata dan Kebudayaan Kabupaten Karo dilakukan dengan uji F (uji Simultan). Hasil uji F dapat dilihat pada tabel 2 berikut ini.

\section{Tabel 2. Uji F ( Uji Simultan))}

\begin{tabular}{|c|c|c|c|c|c|c|}
\hline \multicolumn{7}{|c|}{ ANOVA $^{\mathbf{a}}$} \\
\hline \multicolumn{2}{|c|}{ Model } & Sum of & df & Mean & $\mathrm{F}$ & Sig. \\
\hline \multirow{3}{*}{1} & Regression & 860,009 & 2 & 430,005 & 32,112 &, $000^{\mathrm{b}}$ \\
\hline & Residual & 455,288 & 34 & 13,391 & & \\
\hline & Total & 1315,297 & 36 & & & \\
\hline
\end{tabular}

a. Dependent Variable: Disiplin Kerja

b. Predictors: (Constant), Motivasi, Pengawasan

\section{BerdasarkanTabel 2 dapat} dilihat hasil yang diperoleh nilai $\mathrm{F}$ hitung adalah sebesar 32,112 dan dari nilai table distribusi diperoleh nilai $\mathrm{F}$ tabel sebesar 3,267 maka $F_{\text {hitung }}>\mathrm{F}$ tabel $(32,112>3,267)$ dengan sig. $0,000<0,05$. Maka keputusannya Ho ditolak dan Ha diterima yang berarti secara simultan variabel Pengawasan (X1) dan Motivasi (X2) berpengaruh signifikan terhadap Disiplin kerja pegawai Dinas Pariwisata dan Kebudayaan Kabupaten Karo.

\section{Uji Koefisien Determinasi $\left(\mathbf{R}^{2}\right)$}

Untuk mengukur kemampuan variabel bebas yang dimasukkan dalam model dalam menerangkan variabel depedent maka dilakukan uji Koefisien determinasi yang dapat dapat dilihat pada tabel Model Summary di bawahini :

\section{Tabel 3 Hasil Uji Koefisien Determinasi $\mathbf{R}^{2}$ Model Summary ${ }^{b}$}

\begin{tabular}{|r|c|c|c|c|}
\hline Model & $\mathrm{R}$ & R Square & $\begin{array}{c}\text { Adjusted R } \\
\text { Square }\end{array}$ & $\begin{array}{c}\text { Std. Error of the } \\
\text { Estimate }\end{array}$ \\
\hline 1 & $809^{\mathrm{a}}$ &, 654 &, 633 & 3,659 \\
\hline
\end{tabular}

a. Predictors: (Constant), X2, X1

b. Dependent Variable: Y

Sumber : Data diolah SPSS Versi 21,0 (2017) 
Dari Tabel .3 dapat diketahui nilai $R$ Square sebesar 0,654 atau $65,40 \%$ hal ini dapat diartikan bahwa $65,40 \%$ variabel terikat yaitu Disiplin Kerja pegawai Dinas Pariwisata dan Kebuadayaan Kabupaten Karo dapat dijelaskan oleh variabel bebas yakni variabel Pengawasan (X1) dan variabel Motivasi (X2) dan sisanya sebesar $34,60 \%$ dipengaruhi oleh variabel lain yang tidak dimasukkan dalam model ini.

\section{SIMPULAN}

Berdasarkan hasil analisis dan evaluasi, maka dapat disimpulkan secara parsial variabel pengawasan (X1) dan motivasi berpengaruh signifikan terhadap disiplin kerja pegawai Dinas Pariwisata dan Kebudayaan Kabupaten Karo. Secara simultan dapat dilihat bahwa variabel pengawasan dan motivasi berpengaruh signifikan terhadap disiplin kerja pegawai Dinas Pariwisata Kabupaten Karo. Dari kedua variabel bebas yang paling dominan mempengaruhi disiplin kerja pegawai adalah variabel motivasi. Berdasarkan pengujian koefisien determinasi maka diperoleh nilai Rsquare sebesar $65,40 \%$ ini memberi arti bahwa $65,40 \%$ disiplin kerja pegawai Dinas Pariwisata dan Kebudayaan Kabupaten Karo dipengaruhi oleh pengawasan dan motivasi kerja ssedangkan 34,60\% lagi pengaruhi oleh faktorlain yang tidak diteliti dalam penelitian ini. Saran yang dapat diberikan adalah hendaknya pimpinan perlu memperhatikan hal-hal yang dapat meningkatkan motivasi kerja bawahannya sehingga semua pegawai lebih semangat bekerja. Pengawasan yang dilakukan agar lebih diefektifkan agar setiap pegawai dapat melaksanakan tugasnya sesuai dengan peraturan yang berlaku. Bagi pegawai yang tidak tidak melaksanakan tugasnya dengan disiplin maka pimpinan hendaknya memberikan sanksi sesuai dengan tingkat kesalahan yang mereka lakukan agar memberi efek jera kepada pegawai yang bersangkutan maupun pegawai yang lainnya.

\section{Daftar Pustaka}

Agustini, Fauzia (2011). Manajemen Sumber Daya Manusia Lanjutan. Medan. Madenatera

Athoillah,H.M Anton.(2010) .DasarDasar Manajemen, Bandung . Pusaka Setia

Arikunto, Suharsimi, 2009. Manajemen Penelitian. PT. Rineka Cipta, Jakarta

Handoko, T. Hani. 2008 Manajemen Personalia \& Sumber Daya Manusia.BPFE. Yogjakarta.

Hasibuan, Malayu SP (2010). Manajemen Sumber Daya Manusia.Jakarta.BumiAksar a. 
Kadarisman, M. (2012).Manajemen Pengembangan Sumber Daya Manusia, Jakarta. PT.RajagrafindiPersada.

Mangkunegara,A.A. Anwar Prabu. 2013. .Manajemen Sumber Daya Manusia Perusahaan. Bandung. $\quad$ PT. RemajaRosdaKarya.

Manullang.M. dan Marihot AMH Manullang. 2009. Manajemen

Personalia.Yogjakarta.Gajah Mada University Press.

Manullang,M. 2009. Dasar-Dasar Manajemen. Gajah Mada University Press. Yogjakarta.

Rivai, Veithzal 2011. Manajemen Sumber Daya Manusia Untuk Perusahaan Dari Teori Ke Praktek. Jakarta. PT.Raja grafindo Persada.

Saefullah, Kurniawan dan Sule Ernie Tisnawati 92010) Pengantar Manajemen. Jakarta. Kencana Prenada

Sangadji. Mamang Etta danSopia. 2010. Metodologi Penelitian :Pendekatan Praktis Dalam
Penelitian. Yogyakarta.Andi Offset

Sedarmayanti. 2015. Manajemen

Sumber Daya Manusia :Reformasi Biro krasidan Manajemen Pegawai Negeri Sipil. Jakarta. Aditama.
Sondang.P Siagian. 2015. Manajemen Sumber Daya Manusia. Jakarta. Bumi Aksara.

Sunyoto, Danang. 2013. Manajemen Sumber Daya Manusia, Yogjakarta.CAPS.

Sutrisno, $\quad$ Edy. 2011. ManajemenSumberDayaM anusia. Jakarta. Kencana Prenada.

2011.

BudayaOrganisasi. Jakarta.

Kencana Prenada.

Tri hendradi, C. 2013.Step By Step IBM SPSS 21. Yogyakarta.Andi Offset.

Undang-Undang Nomor 53 Tahun 2010 Tentang Disiplin Pegawai Negeri Sipil. 